\section{(6) OPEN ACCESS}

\title{
Impact of tocilizumab therapy on antibody response to influenza vaccine in patients with rheumatoid arthritis
}

\author{
Shunsuke Mori, ${ }^{1}$ Yukitaka Ueki, ${ }^{2}$ Naoyuki Hirakata, ${ }^{2}$ Motohiro Oribe, ${ }^{3}$ Toshihiko Hidaka, \\ Kazunori Oishi ${ }^{5}$
}

\begin{abstract}
- An additional
supplementary table is published online only. To view this file please visit the journal online (http://dx.doi.org/10. 1136/annrheumdis-2012201950)

${ }^{1}$ Department of Rheumatology, Clinical Research Center for Rheumatic Disease, NHO Kumamoto Saishunsou National Hospital, Kumamoto, Japan

${ }^{2}$ Rheumatic and Collagen Disease Center, Sasebo Chuo Hospital, Nagasaki, Japan ${ }^{3}$ Oribe Rheumachika-Naika Clinic, Oita, Japan ${ }^{4}$ Institute of Rheumatology, Zenjinkai Shimin-no-Mori Hospital, Miyazaki, Japan ${ }^{5}$ Infectious Disease Surveillance Center, National Institute of Infectious Diseases, Tokyo, Japan
\end{abstract}

\section{Correspondence to} Dr Shunsuke Mori, Department of Rheumatology, Clinical Research Center for Rheumatic Disease, NHO Kumamoto Saishunsou National Hospital, 2659 Suya, Kohshi, Kumamoto 861-1196, Japan;

moris@saisyunsou1.hosp.go.jp

Received 7 July 2012

Accepted 26 July 2012

Published Online First

11 August 2012

\section{ABSTRACT \\ Objectives We assessed the influence of tocilizumab} (TCZ), a humanised monoclonal anti-interleukin-6 receptor antibody, on antibody response following influenza vaccination in patients with rheumatoid arthritis (RA). Methods A total of 194 RA patients received inactive trivalent influenza vaccination $(\mathrm{A} / \mathrm{H} 1 \mathrm{~N} 1, \mathrm{~A} / \mathrm{H} 3 \mathrm{~N} 2$ and $\mathrm{B} / \mathrm{B} 1$ strains). All patients were classified into the TCZ $(n=62)$, TCZ+methotrexate (MTX) $(n=49), \operatorname{MTX}(n=65)$ and RA control $(n=18)$ groups. Antibody titres were measured before and 4-6 weeks after vaccination using the haemagglutination inhibitory assay.

Results For the $\mathrm{A} / \mathrm{H} 1 \mathrm{~N} 1$ and $\mathrm{A} / \mathrm{H} 3 \mathrm{~N} 2$ strains, the TCZ and TCZ+MTX groups achieved fold increases of 9.9-14.5, postvaccination seroprotection rates greater than $70 \%$ and seroresponse rates greater than $40 \%$. For the B/B1 strain, seroresponse rates were approximately $30 \%$, but fold increases and seroprotection rates were 5.0-5.4 and greater than $70 \%$, respectively, in these treatment groups. MTX had a negative impact on vaccination efficacy, but adequate responses for protection were nevertheless demonstrated in the MTX group. Neither severe adverse effects nor RA flares were observed.

Conclusions TCZ does not hamper antibody response to influenza vaccine in RA patients. Influenza vaccination is considered effective in protecting RA patients receiving TCZ therapy with or without MTX.

\section{INTRODUCTION}

Influenza vaccination is the most effective method for preventing influenza virus infection and its potentially severe complications. Patients with rheumatoid arthritis (RA) are at an increased risk for infectious diseases due to the nature of RA and its treatment with immunosuppressive agents; ${ }^{1}$ therefore, this patient population is a potential candidate for influenza vaccination. Treatment with antitumour necrosis factor $\alpha$ (anti-TNF $\alpha$ ) agents may impair antibody response to influenza vaccination in patients with RA and other rheumatic diseases, but the response is large enough to warrant influenza vaccination for such patients. ${ }^{2-8}$

Tocilizumab (TCZ), a humanised monoclonal interleukin-6 (IL-6) receptor antibody, is effective in the treatment of patients with moderate to severe RAwho have shown inadequate responses to methotrexate (MTX) and one or more anti-TNF $\alpha$ agents. ${ }^{9}$ Our concern is the impact of TCZ on protective antibody response to influenza vaccination because
IL-6 was originally identified as a factor that plays an essential role in terminal differentiation of $B$ cells into antibody producing plasma cells. ${ }^{10}$ Data regarding the efficacy and safety of influenza vaccination are lacking in RA patients receiving TCZ. Only one attempt at evaluating the efficacy of influenza vaccine has so far been made in a small number of paediatric patients receiving TCZ therapy for systemic onset juvenile idiopathic arthritis. ${ }^{11}$

To address this issue, we determined antibody response to trivalent inactivated influenza vaccine in RA patients being treated with TCZ, MTX or both agents, and compared parameters for efficacy of vaccination among these groups.

\section{METHODS \\ Patients}

RA patients aged 18 or older who had been receiving TCZ (an intravenous infusion of $8 \mathrm{mg} / \mathrm{kg}$ every 4 weeks) for at least 4 weeks and/or MTX (6-18 mg per week) for 12 weeks or more at our rheumatology outpatient clinics were invited to participate in this open-label study. RA patients who had been receiving bucillamine or salazosulphapyridine were also included as RA controls. All participants fulfilled the 1987 American College of Rheumatology criteria for diagnosis of RA. Exclusion criteria were current use of $10 \mathrm{mg} /$ day or more of prednisolone, current use of tacrolimus or leflunomide, a recent history (within 3 months) of influenza infection, and a recent history (within 6 months) of influenza vaccination.

\section{Vaccine}

We used commercially available inactivated trivalent influenza vaccine (Biken HA, Mitsubishi Tanabe Pharm Corporation, Osaka, Japan) containing $30 \mu \mathrm{g}$ of purified haemagglutinin of each of the following: A/California/7/2009 (H1N1)-like strain (A/H1N1 strain), A/Victoria/210/2009 (H3N2)-like strain (A/ H3N2 strain) and B/Brisbane/60/2008-like strain (B/ $\mathrm{B} 1$ strain). Patients received a single dose of vaccine $(0.5 \mathrm{ml})$ subcutaneously from October 2011 until January 2012. For RA patients receiving TCZ, the vaccination was done on the same day as TCZ infusion.

\section{HI tests}

Sera were collected immediately before and 4-6 weeks after vaccination. For the detection of 
influenza antibodies, haemagglutination inhibition (HI) tests were performed in duplicate at SRL (Tachikawa, Tokyo, Japan), according to WHO standard procedure using haemagglutinin antigens representing all three strains that were included in the vaccine. Geometric mean titres (GMTs) of $\mathrm{HI}$ antibodies before and after vaccination, and fold increases relative to prevaccination titres (geometric means of postvaccination to prevaccination antibody titre ratios) were determined. GMTs were calculated from log-transformed values of HI antibody titres. For statistical analysis, a titre of 5 was arbitrarily assigned to sera with undetectable titres of $<10$. Seroprotection was defined as antibody titres of $\geq 40$. Seroconversion was defined as postvaccination antibody titres of $\geq 40$ in patients whose prevaccination titres were $<10$. Seroresponse was defined as seroconversion or fold increases in antibody titres of $\geq 4$ in patients whose prevaccination titres were $\geq 10$.

\section{Monitoring adverse effects and disease activity}

Systemic adverse events and worsening of RA occurring 46 weeks after vaccination were recorded. Systemic adverse effects included fever, tiredness, sweating, myalgia, chills, headache, arthralgia, diarrhoea and common cold-like symptoms. RA activity was monitored using a disease activity score for 28 joints and a clinical disease activity index.

\section{Statistical analysis}

In univariate analyses for categorical variables, differences between treatment groups were analysed using the $\chi^{2}$ test or Fisher's exact probability test. Continuous variables were assessed by the Mann-Whitney $U$ test for comparisons of non- parametric data between the two treatment groups, and analysis of variance with post hoc Tukey's honestly significant difference test for comparisons of parametric data between the four treatment groups. A paired-sample $t$ test was used to compare differences in GMTs between prevaccination and postvaccination.

For all tests, probability values ( $p$ values) $<0.05$ were considered to indicate statistical significance. All calculations were performed using Excel Statistical Analysis 2008 (SSRI Co., Tokyo, Japan) or PASW Statistics V.18 (SPSS Japan Inc., Tokyo, Japan).

\section{RESULTS}

\section{Clinical and demographic characteristics of participants}

A total of 194 RA patients were classified into four groups according to their ongoing anti-RA therapy. One group of 62 patients was treated with TCZ as a monotherapy (TCZ group); 65 patients were treated with MTX alone (MTX group); 49 patients received a combination therapy consisting of TCZ and MTX (TCZ+MTX group); and 18 patients received bucillamine or salazosulphapyridine monotherapy (RA control group). Clinical and demographic characteristics are shown in table 1.

\section{Antibody titres}

After vaccination, GMTs for all strains were increased significantly. Regarding the $\mathrm{A} / \mathrm{H} 3 \mathrm{~N} 2$ strain, a significantly higher post-GMT was obtained in the TCZ group compared with that in the MTX group $(p=0.009)$ (table 2$)$. The TCZ group also showed a higher post-GMT for the B/B1 strain than did the MTX group and the RA control group $(p=0.044$ and $p=0.031$,

Table 1 Clinical and demographic characteristics of RA patients prior to influenza vaccination

\begin{tabular}{|c|c|c|c|c|c|}
\hline & $\begin{array}{l}\text { MTX group } \\
(n=65)\end{array}$ & $\begin{array}{l}\text { TCZ+MTX group } \\
(n=49)\end{array}$ & $\begin{array}{l}\text { TCZ group } \\
(\mathrm{n}=62)\end{array}$ & $\begin{array}{l}\text { RA control } \\
(n=18)\end{array}$ & $\begin{array}{l}\text { p Values between treatment } \\
\text { groups }\end{array}$ \\
\hline Male/female & $11 / 54$ & $5 / 44$ & $11 / 51$ & $3 / 15$ & NS \\
\hline Age, years, mean $(95 \% \mathrm{CI})$ & $67(65.0$ to 68.9$)$ & $62.9(59.8$ to 65.9$)$ & 65.2 (61.6 to 68.8$)$ & $67.3(62.3$ to 72.4$)$ & NS \\
\hline $\begin{array}{l}\text { Prior influenza vaccination, number of patients } \\
(\%)\end{array}$ & $47(72.3)$ & $36(73.5)$ & $50(80.6)$ & $12(66.7)$ & NS \\
\hline RA duration, years, mean (95\% CI) & $9.8(7.7$ to 11.9$)$ & $7.5(5.8$ to 9.2$)$ & $14.6(11.5$ to 17.7$)$ & $11.1(4.8$ to 17.4$)$ & $\begin{array}{l}0.029(\mathrm{M} \text { vs } \mathrm{T}) \\
0.001(\mathrm{~T} / \mathrm{M} \text { vs } \mathrm{T})\end{array}$ \\
\hline $\begin{array}{l}\text { MTX dose, mg/week, median (25th, 75th } \\
\text { percentiles) }\end{array}$ & $8(6,8)$ & $8(6,8)$ & - & - & NS \\
\hline $\begin{array}{l}\text { MTX duration, months, median (25th, 75th } \\
\text { percentiles) }\end{array}$ & $58(17,78)$ & $54(29,89)$ & - & - & NS \\
\hline $\begin{array}{l}\text { TCZ duration, weeks, median (25th, 75th } \\
\text { percentiles) }\end{array}$ & - & $68(24,104)$ & $64(21,107)$ & - & NS \\
\hline Use of prednisolone, number of patients (\%) & $13(20)$ & $12(24.5)$ & $22(35.5)$ & $1(5.6)$ & 0.016 (T vs C) \\
\hline Prednisolone dose, mg/day, mean $(95 \% \mathrm{Cl})$ & $0.87(0.4$ to 1.34$)$ & $0.90(0.33$ to 1.47$)$ & $1.02(0.54$ to 1.49$)$ & - & NS \\
\hline Positive RF, number of patients (\%) & $38(58.5)$ & $42(85.7)$ & $46(74.2)$ & $7(38.9)$ & $\begin{array}{l}0.002 \text { (M vs } \mathrm{T} / \mathrm{M}) \\
0.0001(\mathrm{~T} / \mathrm{M} \text { vs } \mathrm{C}) \\
0.005(\mathrm{~T} \text { vs } \mathrm{C})\end{array}$ \\
\hline Positive anti-CCP Abs, number of patients (\%) & $46(70.8)$ & $43(87.8)$ & $56(90.3)$ & $6(33.3)$ & $\begin{array}{l}0.030 \text { (M vs } \mathrm{T} / \mathrm{M}) \\
0.006 \text { (M vs } \mathrm{T}) \\
0.004(\mathrm{M} \text { vs } \mathrm{C}) \\
<0.0001 \text { (T/M vs } \mathrm{C}) \\
<0.0001 \text { (T vs } \mathrm{C})\end{array}$ \\
\hline CDAI (25th, 75th percentiles) & $5.3(3.7-7.8)$ & $6.2(4.5-7.8)$ & $9.5(7.9-11.1)$ & $8.2(4.8-11.5)$ & $\begin{array}{l}0.001(\mathrm{M} \text { vs } \mathrm{T}) \\
0.027(\mathrm{~T} / \mathrm{M} \text { vs } \mathrm{T})\end{array}$ \\
\hline Lymphocytes, / $\mu \mathrm{l}$, mean (95\% CI) & $\begin{array}{l}1368(1237 \text { to } \\
1500)\end{array}$ & 1395 (1255 to 1535$)$ & $\begin{array}{l}1622(1500 \text { to } \\
1744)\end{array}$ & $\begin{array}{l}1478 \text { (1098 to } \\
1857)\end{array}$ & 0.038 (M vs T) \\
\hline
\end{tabular}

Data were obtained immediately before influenza vaccination. Prior influenza vaccination represents that administered last season (2010/2011). $\mathrm{p}$ Values between treatment groups were determined by the Mann-Whitney U test, post hoc ANOVA using Tukey's HSD test, the $\chi^{2}$ test or Fisher's exact probability test.

ANOVA, analysis of variance; anti-CCP Abs, anti-cyclic citrullinated peptide antibodies; C, RA control group; CDAl, clinical disease activity index; HSD, honestly significant difference; M, MTX group; MTX, methotrexate; NS, not significant; RA, rheumatoid arthritis; RF, rheumatoid factor; T, TCZ group; T/M, TCZ+MTX group; TCZ, tocilizumab. 
Table 2 GMTs and fold increases of $\mathrm{HI}$ antibodies for three influenza strains in the RA treatment groups prior to and after influenza vaccination

\begin{tabular}{|c|c|c|c|c|c|}
\hline & MTX group ( $n=65$ ) & TCZ+MTX group $(n=49)$ & TCZ group $(n=62)$ & RA control group $(n=18)$ & $\begin{array}{l}\text { p Values between } \\
\text { treatment groups }\end{array}$ \\
\hline \multicolumn{6}{|l|}{ GMTs } \\
\hline \multicolumn{6}{|l|}{$\mathrm{A} / \mathrm{H} 1 \mathrm{~N} 1$} \\
\hline After & $120.5(75.3-165.6)^{*}$ & $162.1(86-238.2)^{* *}$ & $211.7(142-281.4)^{*}$ & $169.4(11.5-327.4)^{*}$ & NS \\
\hline \multicolumn{6}{|l|}{$\mathrm{A} / \mathrm{H} 3 \mathrm{~N} 2$} \\
\hline \multicolumn{6}{|l|}{$\mathrm{B} / \mathrm{B} 1$} \\
\hline Before & $45.5(30.2-60.7)$ & $43.2(29.8-56.5)$ & 72.1 (53.3-90.9) & $23.9(12.2-35.6)$ & 0.017 (T vs C) \\
\hline After & $103.1(74.9-131.3)^{*}$ & $105.1(69.4-140.8)^{*}$ & $161.8(123.8-144)^{*}$ & $68.9(45.7-92.1)^{*}$ & $\begin{array}{l}0.044 \text { (M vs T) } \\
0.031 \text { (T vs C) }\end{array}$ \\
\hline \multicolumn{6}{|l|}{ Fold increase } \\
\hline $\mathrm{A} / \mathrm{H} 1 \mathrm{~N} 1$ & $12.6(5.8-19.5)$ & $14.5(7.2-21.9)$ & $12.0(9.8-17.7)$ & $11.2(3.0-19.4)$ & NS \\
\hline
\end{tabular}

Data are expressed as the mean $(95 \%$ Cls). Differences between prevaccination and postvaccination GMTs were assessed using the paired-sample $t$ test. Comparisons between the four treatment groups were performed by post hoc ANOVA using Tukey's HSD test.

${ }^{*} \mathrm{p}<0.0001,{ }^{* *} \mathrm{p}=0.009$ and ${ }^{* * *} \mathrm{p}=0.001$ based on comparisons with prevaccination titres.

ANOVA, analysis of variance; C, RA control group; GMT, geometric mean titre; HI, haemagglutination inhibition; HSD, honestly significant difference; M, MTX group; MTX, methotrexate; NS, not significant; RA, rheumatoid arthritis; T, TCZ group; TCZ, tocilizumab.

respectively). Fold increases in GMTs for the three strains were $\geq 3.5$-fold in all treatment groups. These groups achieved similar levels of fold increases for each strain and there were no statistically significant differences.

\section{Seroprotection, seroresponse and seroconversion rates}

After vaccination, seroprotection rates for the three influenza strains were increased significantly in all treatment groups (figure 1A). The TCZ and TCZ+MTX groups achieved postvaccination protection rates of $>70 \%$ for all the influenza strains. Regarding the $\mathrm{A} / \mathrm{H} 3 \mathrm{~N} 2$ and $\mathrm{B} / \mathrm{B} 1$ strains, postvaccination seroprotection rates were significantly higher in the TCZ group compared with those in the other three treatment groups (for $\mathrm{A} / \mathrm{H} 3 \mathrm{~N} 2, \mathrm{p}<0.0005$ vs MTX, $\mathrm{p}=0.001$ vs TCZ + MTX $\mathrm{p}=0.006$ vs RA control; for B/B1, $p=0.007$ vs MTX, $p=0.023$ vs TCZ + MTX, $p=0.007$ vs RA control). Seroprotection rates for the A/ H1N1 strain were similar among all the groups tested.

For the $\mathrm{A} / \mathrm{H} 1 \mathrm{~N} 1$ and $\mathrm{A} / \mathrm{H} 3 \mathrm{~N} 2$ strains, seroresponse rates were $>40 \%$ in the MTX, TCZ and TCZ+MTX groups, while the rates for the $\mathrm{B} / \mathrm{B} 1$ strain in these groups were approximately $30 \%$ (figure $1 \mathrm{~B}$ ). The seroresponse rate for the $\mathrm{A} / \mathrm{H} 3 \mathrm{~N} 2$ strain was significantly higher in the TCZ group compared with that in the MTX group $(p=0.04)$. Seroconversion rates for the three influenza strains were greater than $40 \%$ in all treatment groups (figure 1C). The TCZ group showed a significantly higher seroconversion rate for the A/H3N2 strain than did the MTX group $(p=0.032)$.

\section{Predictive factors for seroresponse to influenza vaccination}

In multivariate logistic regression analysis, TCZ use was not identified as the predictive factor for seroresponse to influenza vaccination (see online supplementary table S1). For the A/ H3N2 strain, the negative association of current MTX use with seroresponse was confirmed $(p=0.04)$. Prior influenza vaccination was negatively associated with seroresponse for all the three strains (for $\mathrm{A} / \mathrm{H} 1 \mathrm{~N} 1, \mathrm{p}=0.006$; for $\mathrm{A} / \mathrm{H} 3 \mathrm{~N} 2, \mathrm{p}=0.01$; for $\mathrm{B} / \mathrm{B} 1, \mathrm{p}<0.0001)$. This may have reflected ceiling effects; that is, higher prevaccination protection rates may, at least in part, have influenced the observed seroresponse rates.

\section{Vaccination safety}

Neither systemic adverse effects nor exacerbation of RA was experienced by any patients during a follow-up period of 46 weeks after vaccination.

\section{DISCUSSION}

Antibody response to the $\mathrm{A} / \mathrm{H} 1 \mathrm{~N} 1$ and $\mathrm{A} / \mathrm{H} 3 \mathrm{~N} 2$ strains in the TCZ and TCZ+MTX groups met all three requirements of the European Medicines Agency (EMA) guidance for assessment of influenza vaccines specified by the Committee for Proprietary Medical Products (CPMP). ${ }^{12}$ For the B/B1 strain, these treatment groups met two of the EMA/CPMP criteria. The MTX group fulfilled two of the EMA/CPMP criteria for all strains. Multivariate logistic analysis confirmed that TCZ use is not a predictive factor for inadequate antibody response for any influenza strain.

IL-6 works as a B cell differentiation factor, which induces activated $\mathrm{B}$ cells to produce immunoglobulin. ${ }^{10}$ The blockage of IL-6 activity following TCZ therapy, therefore, would be expected to reduce humoral immune response to influenza vaccination. Kopf et $a l^{13}$ indicated that $\mathrm{T}$ cell-dependent antibody response against virus infection is impaired in IL-6-deficient mice. Unlike anti-infliximab or antiadalimumab antibodies, anti-TCZ antibodies rarely developed in RA patients receiving $8 \mathrm{mg} / \mathrm{kg}$ of TCZ, even as monotherapy. ${ }^{14} 15$ Nevertheless, the present study has clearly indicated that RA patients receiving TCZ therapy can be effectively and safely immunised with influenza vaccine. One possible explanation may be that, unlike rituximab, TCZ is not a B cell-targeting antibody that can induce $B$ cell depletion. Given that a variety of cytokines are released from activated helper $\mathrm{T}$ cells, antibody production may not depend simply on IL-6. Costelloe et $a 1^{16}$ showed that IL-6 is not required for antigen (influenza virus)-specific antibody responses by non-fractionated tonsillar mononuclear cells or by $\mathrm{T}$ cell-depleted B cells in the presence of IL-2. Another explanation may be that IL-6 signalling is not inhibited completely in lymphoid tissue, locations in which vaccination-mediated immune response is initiated, even when maximum saturation of soluble IL- 6 receptors in the circulation is achieved with 
$\square$ Cont $\square$ MTX $\square \mathrm{TCZ} \square \mathrm{TCZ}+\mathrm{MTX}$
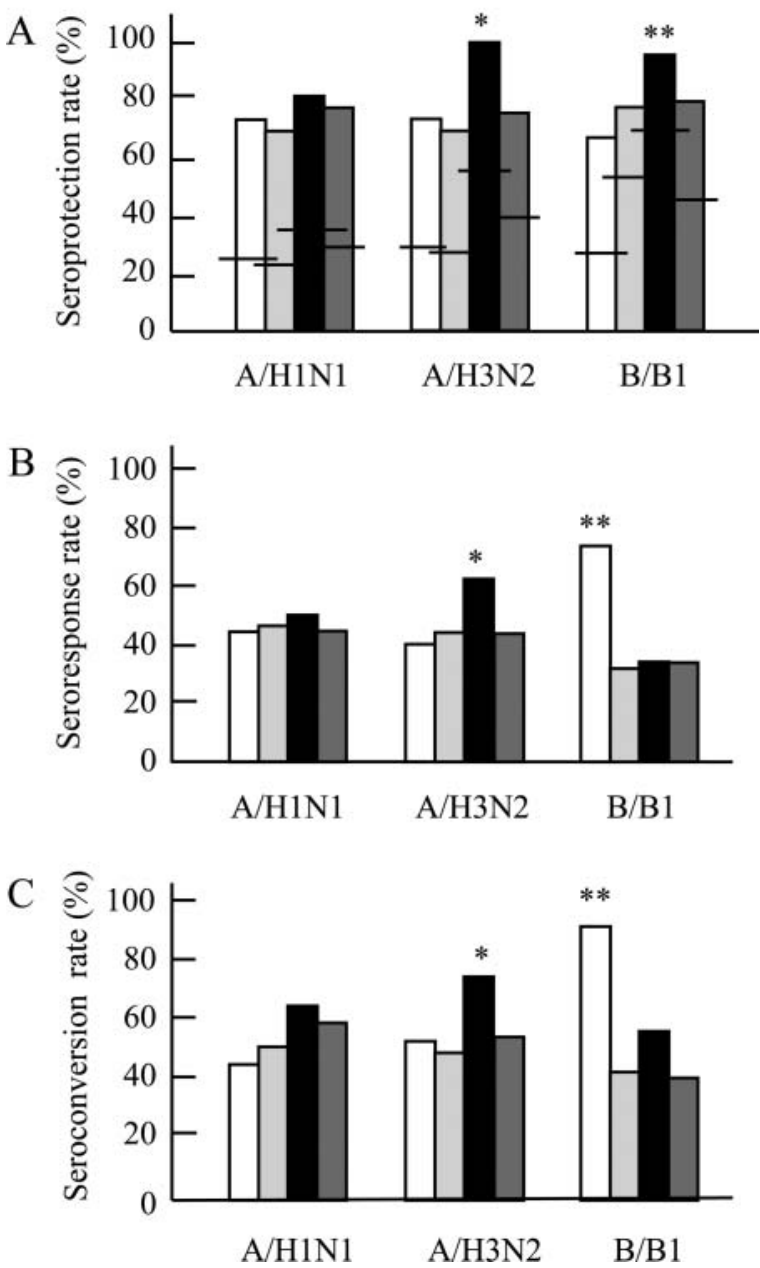

Figure 1 (A) Seroprotection rates for three influenza strains in the RA treatment groups prior to and after influenza vaccination. Horizontal bars represent levels of prevaccination protection rates for each influenza strain. ${ }^{*} p=0.006$ (TCZ vs Cont), $p<0.0005$ (TCZ vs MTX) and $p=0.001$ (TCZ vs TCZ+MTX). ${ }^{*} p=0.007$ (TCZ vs Cont, TCZ vs MTX) and $p=0.023$ (TCZ vs TCZ+MTX). (B) Seroresponse rates for three influenza strains in the RA treatment groups. ${ }^{*} p=0.04$ (TCZ vs MTX). ${ }^{* *} p=0.0009$ (Cont vs MTX), $p=0.002$ (Cont vs TCZ) and $p=0.022$ (Cont vs TCZ+MTX). (C) Seroconversion rates for three influenza strains in the RA treatment groups. Seroconversion rates are expressed as percentages of patients with seroconversion out of seronegative patients before vaccination (antibody titres $<10$ ). ${ }^{*} \mathrm{p}=0.032$ (TCZ vs MTX). ${ }^{* *} \mathrm{p}=0.003$ (Cont vs MTX) and $p=0.002$ (Cont vs TCZ+MTX). Data were compared using the $\chi^{2}$ test or Fisher's exact probability test. Cont, RA control group; MTX, methotrexate group; RA, rheumatoid arthritis; TCZ, tocilizumab group; TCZ + MTX, combination therapy group.

TCZ. Uchiyama et $a l^{17}$ reported that anti-TCZ antibodies are induced in monkeys receiving $30 \mathrm{mg} / \mathrm{kg}$ of TCZ weekly, suggesting that IL-6 does not play a crucial role in antibody production.

Most previous studies have shown that the use of MTX is unlikely to affect antibody response to influenza vaccine..$^{2-4} 718$ However, Gabay et a ${ }^{19}$ have indicated that MTX significantly reduced responsiveness to AS03-adjuvanted pandemic $\mathrm{H} 1 \mathrm{~N} 1$ 2009 (A/H1N1/2009) vaccine in patients with rheumatic diseases. The mechanism by which MTX impairs antibody response following vaccination is unknown, but several studies have proposed that MTX prevents proliferation of $\mathrm{T}$ cells and induces apoptosis in these cells. ${ }^{20}$
In conclusion, despite TCZ therapy, the immunogenicity of influenza vaccination appears to be conserved and sufficient in RA patients. MTX had a negative impact on vaccination efficacy, but adequate immune responses for protection were achieved by RA patients in the MTX and MTX+TCZ groups. Neither severe adverse effects nor RA flares were observed following vaccination. RA patients, even those receiving TCZ as monotherapy or in a combination therapy with MTX, should therefore be encouraged to receive influenza vaccination.

Contributors All authors contributed to study conception and design, acquisition of data, analysis and interpretation of data, and drafting of the manuscript with regard to important intellectual content.

Funding The study was supported by research funds from the National Hospital Organisation (NHO), Japan.

Competing interests None.

Patient consent Obtained.

Ethics approval The ethics committees of participating hospitals approved the protocol for this study.

Provenance and peer review Not commissioned; externally peer reviewed.

\section{REFERENCES}

1. Doran MF, Crowson CS, Pond GR, et al. Frequency of infection in patients with rheumatoid arthritis compared with controls: a population-based study. Arthritis Rheum 2002; 46:2287-93.

2. Fomin I, Caspi D, Levy V, et al. Vaccination against influenza in rheumatoid arthritis: the effect of disease modifying drugs, including TNF alpha blockers. Ann Rheum Dis 2006;65:191-4.

3. Kapetanovic MC, Saxne T, Nilsson JA, et al. Influenza vaccination as model for testing immune modulation induced by anti-TNF and methotrexate therapy in rheumatoid arthritis patients. Rheumatology (Oxford) 2007;46:608-11.

4. Kaine JL, Kivitz AJ, Birbara C, et al. Immune responses following administration of influenza and pneumococcal vaccines to patients with rheumatoid arthritis receiving adalimumab. J Rheumatol 2007;34:272-9.

5. Kubota T, Nii T, Nanki T, et al. Anti-tumor necrosis factor therapy does not diminish the immune response to influenza vaccine in Japanese patients with rheumatoid arthritis. Mod Rheumatol 2007:17:531-3.

6. Gelinck LB, van der Bijl AE, Beyer WE, et al. The effect of anti-tumour necrosis factor alpha treatment on the antibody response to influenza vaccination. Ann Rheum Dis 2008;67:713-16.

7. Elkayam 0, Bashkin A, Mandelboim M, et al. The effect of infliximab and timing of vaccination on the humoral response to influenza vaccination in patients with rheumatoid arthritis and ankylosing spondylitis. Semin Arthritis Rheum 2010;39:442-7.

8. Salemi S, Picchianti-Diamanti A, Germano V, et al. Influenza vaccine administration in rheumatoid arthritis patients under treatment with TNF alpha blockers: safety and immunogenicity. Clin Immunol 2010;134:113-20.

9. Patel AM, Moreland LW. Interleukin-6 inhibition for treatment of rheumatoid arthritis: a review of tocilizumab therapy. Drug Des Devel Ther 2010;4:263-78.

10. Muraguchi A, Hirano T, Tang B, et al. The essential role of B cell stimulatory factor 2 (BSF-2/LL-6) for the terminal differentiation of B cells. J Exp Med 1988; 167:332-44.

11. Shinoki T, Hara R, Kaneko U, et al. Safety and response to influenza vaccine in patients with systemic-onset juvenile idiopathic arthritis receiving tocilizumab. Mod Rheumatol. Published Online First: 11 February 2012

12. Committee for proprietary medical products (CPMP). Note for guidance on harmonization of requirements for influenza vaccination. London: The European Agency for the Evaluation of Medicinal Products (EMEA/CPMP/BMP/214/96). 1997:1-18

13. Kopf M, Baumann H, Freer G, et al. Impaired immune and acute-phase responses in interleukin-6-deficient mice. Nature 1994;368:339-42.

14. Nishimoto N, Hashimoto J, Miyasaka N, et al. Study of active controlled monotherapy used for rheumatoid arthritis, an IL-6 inhibitor (SAMURAI): evidence of clinical and radiographic benefit from an $\mathrm{x}$ ray reader-blinded randomised controlled trial of tocilizumab. Ann Rheum Dis 2007;66:1162-7.

15. Maini RN, Taylor PC, Szechinski J, et al. Double-blind randomized controlled clinical trial of the interleukin-6 receptor antagonist, tocilizumab, in European patients with rheumatoid arthritis who had an incomplete response to methotrexate. Arthritis Rheum 2006;54:2817-29.

16. Costelloe $\mathbf{K E}$, Smith $\mathbf{S H}$, Callard RE. Interleukin 6 is not required for antigen-specific antibody responses by human B cells. Eur $\mathrm{J}$ Immunol 1993;23:984-7. 
17. Uchiyama Y, Yorozu K, Hashizume M, et al. Tocilizumab, a humanized anti-interleukin-6 receptor antibody, ameliorates joint swelling in established monkey collagen-induced arthritis. Biol Pharm Bull 2008;31:1159-63.

18. Abu-Shakra M, Press J, Varsano N, et al. Specific antibody response after influenza immunization in systemic lupus erythematosus. J Rheumatol 2002:29:2555-7.
19. Gabay C, Bel M, Combescure C, et al. Impact of synthetic and biologic disease-modifying antirheumatic drugs on antibody responses to the ASO3-adjuvanted pandemic influenza vaccine: a prospective, open-label, parallel-cohort, single-center study. Arthritis Rheum 2011;63:1486-96.

20. Wessels JA, Huizinga TW, Guchelaar HJ. Recent insights in the pharmacological actions of methotrexate in the treatment of rheumatoid arthritis. Rheumatology (Oxford) 2008:47:249-55. 